\title{
Belonging as Compensator
}

\section{Social Belonging Moderates the Relation Between Bullying and Well-Being Worldwide}

\author{
Tamara Marksteiner ${ }^{1}$, Marc Philipp Janson ${ }^{1}$, and Hanna Beißert ${ }^{2}$ \\ 1Department of Educational Psychology University of Mannheim, Germany \\ ${ }^{2}$ DIPF | Leibniz Institute for Research and Information in Education, Frankfurt am Main, Germany
}

\begin{abstract}
Bullying is a serious issue among adolescents worldwide. It has been conceptualized as a type of physical or indirect peer victimization that occurs repeatedly over time and is characterized by a systematic abuse of power. Being bullied at school severely affects victims' health and well-being. What protects students from these consequences? We investigate feelings of belonging -i.e., the feeling that one is accepted, included, respected, and valued in the respective social environment - as a possible compensator for bullying consequences across different cultures. We hypothesize that being bullied is less severe for students who have strong feelings of belonging. We use data from 319,057 15-year-old students across 47 countries. Multilevel regression analyses replicated that bullying and well-being are negatively associated. Further, the results indicated, as expected, that feelings of belonging compensate for the negative impact that bullying has on well-being. Practical implications as well as limitations are discussed.
\end{abstract}

Keywords: bullying, social belonging, well-being, life satisfaction, cross-cultural research, multilevel regression

Soziale Zugehörigkeit moderiert den Zusammenhang von Mobbing und Wohlbefinden weltweit

Zusammenfassung: Mobbing ist ein ernstes Problem bei Jugendlichen weltweit. Es wird als eine Art physische oder indirekte Peer-Viktimisierung verstanden, die im Laufe der Zeit wiederholt auftritt und durch einen systematischen Machtmissbrauch gekennzeichnet ist. Gemobbt zu werden beeinträchtigt die Gesundheit und das Wohlbefinden der Opfer erheblich. Was schützt die Schüler vor diesen Folgen? Wir untersuchen Zugehörigkeitsgefühle - d.h. das Gefühl, im jeweiligen sozialen Umfeld akzeptiert, einbezogen, respektiert und geschätzt zu werden - als möglichen Kompensator für Mobbing-Konsequenzen in verschiedenen Kulturen. Wir nehmen an, dass es für Schüler mit starkem Zugehörigkeitsgefühl weniger schwerwiegend ist, gemobbt zu werden. Wir verwenden Daten von N=319.057 15-jährigen Schülern aus 47 Ländern. Mehrebenen-Regressionsanalysen zeigen, dass Mobbing und Wohlbefinden negativ korrelieren. Darüber hinaus zeigen die Ergebnisse erwartungsgemäß, dass Zugehörigkeitsgefühle die negativen Auswirkungen von Mobbing auf das Wohlbefinden kompensieren. Praktische Implikationen sowie Einschränkungen werden diskutiert.

Schlüsselwörter: Mobbing, Soziale Zugehörigkeit, Wohlbefinden, Mehrebenen-Regressionen

Bullying is a serious issue among children and adolescents and has been investigated in numerous studies worldwide (Carbone-Lopez et al., 2010; Cook et al., 2010). Bullying has been conceptualized as a type of peer victimization repeatedly occurring over time and is characterized by a systematic abuse of power; it can include physical harm or indirect forms of victimization (Alsaker, 2017. Thus, a victim of bullying can be physically (hit, punched, or kicked) or verbally (called names or mocked) abused or socially excluded (e.g., ignored, excluded from games; Organization for Economic Cooperation and Development [OECD], 2017a; see also Solberg \& Olweus, 2003). Children and adolescents who have been bullied suffer from serious health and well-being problems: For example, they show signs of mild-to-severe depression (Austin \& Joseph, 1996) and have lower self-esteem (e.g., Esben- sen \& Carson, 2009). However, the prevalence of bullying incidents is alarmingly high: According to the United Nations Educational, Scientific, and Cultural Organization (UNESCO) report, across all regions worldwide, almost one third of students have been bullied by their schoolmates at least once in the last month (UNESCO, 2019). Thereby, physical bullying is the most common and sexual bullying the second most frequent form of bullying.

What protects students from those negative consequences of being bullied at school? We propose that one factor that can serve as a compensator is their feeling of belonging, that is, the feeling of being accepted, included, respected, and valued in the respective social environment (Walton \& Brady, 2017). In line with this, we hypothesize that being bullied at school is less severe for 
students who have strong feelings of belonging and inclusion. Most previous studies focus on bullying prevention (e.g., Olweus \& Limber, 2010) or on factors related to bullying. In contrast to most of the previous research, we focus on factors that mitigate the negative consequences of bullying. More specifically, we focus on social belonging as a moderator of the negative relation between bullying and students' well-being. So far, moderators of this relation have not been investigated, especially not cross-culturally. Therefore, for the first time, the present study investigates the possible compensatory effects of belonging across several countries.

\section{Bullying at School and Well-Being}

Children and adolescents spend huge parts of their lives in educational settings. Thus, many of their social relations develop at school. Positive social relations at school are of great importance for students' achievement, health, and well-being (Ganotice \& King, 2014; Juvonen, 2006; Roseth et al., 2008; Walton \& Cohen, 2007; Wentzel et al. , 2004). However, bullying is a widespread problem in schools all over the world (Blazer, 2005; Carney \& Merrell, 2001; Cook et al., 2010; Eslea et al., 2004; Kanetsuna \& Smith, 2002). Like many psychological concepts, bullying is defined and conceptualized in different ways. In the present paper, we refer to the definition by Olweus (1996), who considers a student as being bullied, "when he/she is exposed, repeatedly and over time, to negative actions on the part of one or more other students" (p. 334). Importantly, to be understood as bullying, these behaviors have to take place frequently and the victim can hardly defend himself/herself. In line with this, Olweus considers friendly and playful teasing and two students of about the same strength or power who argue or fight not to be bullying.

In a meta-analysis of studies around the world, depending on the specific way that bullying is defined and measured, prevalence rates range from $10 \%$ to $30 \%$ (Cook et al., 2010). Throughout school, these rates follow an inverted U-shaped course: They increase through elementary school with the highest rates in middle school and decrease around the end of secondary education (Hazler, 1996; Northwest Regional Educational Laboratory, 2001; Olweus, 1993).

Bullying at school represents a major issue in the development of children and adolescents. Being bullied can have severe consequences for students' health and well-being as well as for their social development and academic achievement (Hawker \& Boulton, 2000; Rigby, 2003). Regarding their health and well-being, for in- stance, bullying is associated with low self-esteem (Austin \& Joseph, 1996; Esbensen \& Carson, 2009; Seals \& Young, 2003), and anxiety (Esbensen \& Carson, 2009; Kaltiala-Heino et al., 2000). Regarding academic achievement, bullying is associated with lower engagement at school as well as lower academic achievement (Buhs et al., 2006; Juvonen, 2006), poorer academic self-concept (Buhs, 2005), and higher school avoidance (Hutzell \& Payne, 2012). Again, like many psychological concepts, well-being is defined and conceptualized in different ways. In the present paper, we refer to the definition by Schimmack and colleagues (2002, p. 582), who state that definitions of subjective well-being distinguish between an affective and a cognitive component. While the affective component is an individual's balance between pleasant and unpleasant affect, the cognitive component is an individual's life satisfaction, that is, the evaluation of one's life according to subjectively determined standards. In the current study, we focus on life satisfaction as the cognitive component of well-being.

Given these serious implications of bullying for children's and youths' development, it is on the one hand indispensable to implement intensive prevention programs in order to reduce bullying rates. However, on the other hand, it is important to identify aspects that help children cope with being bullied at school. We consider social belonging as a buffering factor that, as we assume, reduces the impact of being bullied on students' wellbeing.

\section{Social Belonging as Compensator}

Relatedness or social belonging is considered a fundamental human motivation that guides human behavior. It is crucial for human survival and for maintaining lasting, positive, and significant interpersonal relationships (Baumeister \& Leary, 1995; Deci \& Ryan, 2008). In educational settings, students also feel the need to form and maintain meaningful relationships with their peers. Especially in educational settings, past research demonstrated the positive effects of strong feelings of belonging: For example, research has shown that feelings of belonging increased students' health at an American college (e.g., Walton \& Cohen, 2011), were negatively related to depression symptoms (Choenarom et al., 2005; Hagerty et al., 1992; Hoyle \& Crawford, 1994), to emotional burden (Skaalvik \& Skaalvik, 2011), social anxiety (Hoyle \& Crawford, 1994), and even to suicidal ideation or actual suicide (Gunn et al., 2012; Van Orden et al., 2012). Moreover, belonging negatively relates to students' emotional exhaustion - a core element of burnout (see 
Maslach et al., 1986). Summed up, social belonging is an important variable in educational settings.

But why would belonging serve as a compensator in the context of bullying? One can assume that the feeling of acceptance and appreciation makes people more resilient toward well-being-threatening incidents like bullying. For example, Lee and Williams (2013) explored the relationships between parental alcoholism, sense of belonging, resilience, and depressive symptoms. Their results indicate that sense of belonging was the most powerful factor for resisting depressive symptoms associated with parental alcoholism. Moreover, resilience served as a mediator between the direct effect of feelings of belonging on depressive symptoms. Also, Alizadeh et al. (2018) found a significant positive relation between feelings of belonging and resilience among women with breast cancer. In a longitudinal study, Scarf et al. (2016) also found that feelings of belonging predicted long-term increases in adolescents' resilience. However, the exact psychological mechanisms are to be investigated in future research.

Further, Walton et al. (2015) argue that students with strong feelings of belonging reacted differently to threatening events in the educational context (like an unfriendly email from a professor) than did students with less strong feelings of belonging. For example, Walton's research findings demonstrated that Black students at an American university with mainly White students or women in a male-dominated major usually had doubts about their belonging. Thus, they usually perceived potentially threatening events as evidence of their non-belonging. However, if these students, nevertheless, had strong feelings of belonging, they instead explained these events by unfortunate circumstances (like a moody professor) than by their non-belonging, which represents a much more functional attribution style. Past research supports this explanation (Walton \& Cohen, 2011). On the basis of these findings, we assume that feelings of belonging can also serve as a compensator for bullying: For example, a student who is bullied but, still, has strong feelings of belonging might also explain bullying behavior not as evidence that he/she is, for example, worthless; he/she might explain bullying behavior or something situational, for example, as an act of jealousy. Thus, students with strong feelings of belonging might attribute or explain negative social events externally or with reasons that are not threatening to their general feeling of being accepted by others or their well-being (Weiner, 2010). So far, no research explicitly investigated the proposed compensating effects of social belonging.

\section{The Present Study}

The aim of the present study was to investigate the possible compensating effect of feelings of belonging on the negative consequences of bullying on well-being for students worldwide. First, we tested the empirically wellinvestigated negative relation between bullying and students' life satisfaction as our measurement of student's well-being across several countries. Second, and more importantly, we tested whether feelings of belonging can mitigate the negative effects of bullying on life satisfaction for students worldwide. We assume that the stronger the students' feelings of social belonging are, the weaker the negative relation between bullying and life satisfaction. Thus, we expect an interaction effect between bullying and feelings of belonging on students' life satisfaction.

\section{Method}

\section{Data Source and Sample}

To test our hypotheses, we used the PISA 2015 dataset that contains data from more than half a million 15-yearold students in 72 countries worldwide. The dataset includes data on students' achievement, self-reports on well-being, as well as information on socioeconomic background. Due to missing scales in some countries, we were only able to use data from 319,057 students $(162,275$ female, 156,782 male) from 11,699 schools across 47 countries.

\section{Measures}

\section{Bullying}

For the first time, the PISA 2015 dataset contains an 8item scale for measuring bullying in school. However, in most countries only six of the items were used. Students were asked how often they had experienced bullying behavior by other students in the past 12 months. The items were, for example, "I got called names by other students"; "Other students left me out of things on purpose"; and "I got hit or pushed around by other students." The answer options were $1=$ never or almost never, 2 = a few times a year, 3 = a few times a month, and 4 = once $a$ week or more. As the data for bullying showed a strongly skewed distribution (with most students reporting no bullying experiences), no scale was built and included in the PISA data file and no internal consisten- 
cies reported in the technical report (OECD, 2017b). Therefore, we computed mean scores for each student of our sample using the 6-item scale and checked for measurement invariance in our preliminary analyses.

\section{Life Satisfaction}

Also, for the first time, in 2015, the PISA dataset contains information about students' well-being. Students reported their general life satisfaction on a single-item scale "Overall, how satisfied are you with your life as a whole these days?" - with a range from 0 to 10, higher values indicating a higher life satisfaction. According to Cheung and Lucas (2014), this single-item approach does not lack predictive validity in comparison with scales using more items.

\section{Belonging}

The PISA 2015 dataset also includes a 6-item scale measuring students' school belonging (OECD, 2017b). The scale consists of items like "I make friends easily at school" or inverted ones like "I feel like an outsider (or left out of things) at school" answerable on a 4-point Likert scale with the answering categories $1=$ strongly agree, $2=$ agree, 3 = disagree, and $4=$ strongly disagree. Internal consistencies of the scale across countries can be seen as a sufficient indicator of reliability (Cronbach's $\alpha=$ .69-.90). We included the estimated IRT parameter of each student in our analysis provided in the PISA dataset.

\section{Analytical Procedure}

\section{Preliminary Analyses}

First, as the PISA dataset contains no validated indicator for bullying, we checked for measurement invariance for our own mean score using confirmatory factor analyses comparing the comparative fit index (CFI) and the root mean square error of approximation (RMSEA). With respect to the hierarchical data structure of the PISA dataset with students nested in schools and schools nested in countries, a multilevel regression seems to be appropriate. To inspect whether a multilevel approach is adequate for our dataset, we computed intraclass correlations (ICC). Even small ICC values of .05 or .01 lead to biased significance tests in Ordinary Least Squares (OLS) regressions (Cohen et al., 2003, p. 538). To maintain interpretability of the cross-level interactions, we groupcentered all predictors (Enders \& Tofighi, 2007; Hofmann \& Gavin, 1998). We used the lme4 package (Bates et al., 2014) for our analysis and selected the bobyqa optimizer for maximum likelihood estimation (Nash \& Varadhan, 2011). As we are aware of the problems regarding the sampling structure of the PISA dataset, we included sampling weights in our analyses using the method described by Carle (2009). We compared models regarding model fit using information criteria and, if appropriate, chi-square statistics. We considered the high sample size and tested our hypotheses on a $1 \%$ alpha level.

\section{Analysis 1: The Relation Between Bullying and Life Satisfaction}

First, we inspected the relation between bullying and life satisfaction alone and, afterwards, together with the main effects of the moderating variables on individual level (L1). In addition to random intercepts, we allowed for random slopes of bullying to inspect deviations of the association across schools and countries and tested those using likelihood ratio tests of the lmer test package (Kuznetsova et al., 2014).

\section{Analysis 2: Belonging as Moderator of the Relation Between Bullying and Life Satisfaction}

The aim of this study was to test whether the bullyingand-life-satisfaction association is stable across countries and if belonging on different levels does moderate this link. Therefore, we entered the interaction between bullying and belonging. Assuming a negative main effect of bullying, a positive interaction term would indicate a less predictive power of bullying for individuals with stronger feelings of belonging.

In all analyses, we added gender, socioeconomic status (economic, social, and cultural status [ESCS]), and migration background as control variables.

\section{Results}

Descriptive statistics and bivariate correlations of the variables used in our analyses are presented in Tables 1 and 2. The multigroup confirmatory factor analyses revealed sufficient measurement invariance on a configural $(\mathrm{CFI}=.944$; RMSEA $=.115)$ and loading level $(\mathrm{CFI}=$ .924; RMSEA $=.107)$ but insufficient on intercept $(\mathrm{CFI}=$ .896; RMSEA = .108) and mean level $(\mathrm{CFI}=.885$; RMSEA $=.111$ ). ICCs retrieved from the null-model with countries and schools as clustering variables indicate substantial variations of intercepts of well-being across countries, ICC $=.04$, and schools, ICC $=.02$. Taking those and the hierarchical data structure of the PISA dataset into account, we followed the multilevel approach. 
Table 1. Mean and standard deviation for life satisfaction, feelings of belonging, and bullying by country

\begin{tabular}{|c|c|c|c|c|c|c|c|}
\hline \multirow[t]{2}{*}{ Country } & \multicolumn{2}{|c|}{ Life satisfaction } & \multicolumn{2}{|c|}{ Belonging } & \multicolumn{2}{|c|}{ Bullying } & \multirow[b]{2}{*}{$n$} \\
\hline & $M$ & $S D$ & $M$ & $S D$ & $M$ & $S D$ & \\
\hline ARE & 7.30 & 2.49 & -0.07 & 0.89 & 1.40 & 0.62 & 13,011 \\
\hline AUT & 7.57 & 2.15 & 0.46 & 1.27 & 1.27 & 0.46 & 6,832 \\
\hline BEL & 7.50 & 1.95 & 0.05 & 0.88 & 1.27 & 0.42 & 3,660 \\
\hline BGR & 7.45 & 2.46 & -0.31 & 0.95 & 1.35 & 0.56 & 5,227 \\
\hline BRA & 7.56 & 2.38 & -0.12 & 1.00 & 1.25 & 0.49 & 17,813 \\
\hline $\mathrm{CHE}$ & 7.66 & 1.98 & 0.34 & 1.06 & 1.26 & 0.43 & 5,685 \\
\hline $\mathrm{CHL}$ & 7.45 & 2.23 & 0.05 & 1.06 & 1.26 & 0.43 & 6,823 \\
\hline $\mathrm{COL}$ & 7.79 & 2.37 & -0.31 & 1.03 & 1.34 & 0.46 & 11,166 \\
\hline CRI & 8.20 & 2.12 & -0.14 & 1.21 & 1.28 & 0.47 & 5,838 \\
\hline CZE & 7.06 & 2.26 & -0.23 & 0.78 & 1.33 & 0.53 & 6,613 \\
\hline DEU & 7.35 & 2.13 & 0.32 & 1.06 & 1.23 & 0.40 & 5,424 \\
\hline DOM & 8.53 & 2.24 & -0.34 & 1.24 & 1.36 & 0.60 & 4,094 \\
\hline ESP & 7.45 & 2.03 & 0.49 & 1.16 & 1.22 & 0.41 & 6,471 \\
\hline EST & 7.48 & 2.11 & -0.06 & 0.87 & 1.29 & 0.47 & 5,447 \\
\hline FIN & 7.89 & 1.84 & 0.10 & 0.98 & 1.27 & 0.45 & 5,716 \\
\hline FRA & 7.64 & 1.89 & -0.04 & 0.78 & 1.23 & 0.43 & 5,759 \\
\hline GBR & 7.11 & 2.27 & -0.07 & 0.91 & 1.35 & 0.56 & 13,379 \\
\hline GRC & 6.92 & 2.26 & 0.13 & 0.97 & 1.21 & 0.44 & 5,328 \\
\hline$H K G$ & 6.51 & 2.03 & -0.34 & 0.70 & 1.42 & 0.62 & 5,181 \\
\hline HRV & 7.90 & 2.04 & 0.06 & 0.96 & 1.25 & 0.44 & 5,646 \\
\hline HUN & 7.18 & 2.26 & 0.08 & 1.01 & 1.28 & 0.50 & 5,449 \\
\hline $\mathrm{IRL}$ & 7.31 & 2.13 & -0.01 & 0.94 & 1.25 & 0.43 & 5,628 \\
\hline ISL & 7.81 & 2.18 & 0.21 & 1.29 & 1.18 & 0.39 & 3,224 \\
\hline JPN & 6.82 & 2.28 & -0.02 & 0.90 & 1.28 & 0.47 & 6,502 \\
\hline KOR & 6.36 & 2.34 & 0.16 & 0.89 & 1.12 & 0.29 & 5,514 \\
\hline LTU & 7.85 & 2.14 & -0.28 & 1.10 & 1.27 & 0.49 & 6,160 \\
\hline LUX & 7.39 & 2.18 & 0.16 & 1.06 & 1.23 & 0.46 & 5,077 \\
\hline LVA & 7.37 & 2.00 & -0.20 & 0.87 & 1.45 & 0.56 & 4,740 \\
\hline MAC & 6.60 & 2.12 & -0.40 & 0.62 & 1.40 & 0.56 & 4,461 \\
\hline MEX & 8.28 & 1.98 & -0.13 & 1.09 & 1.29 & 0.50 & 7,348 \\
\hline MNE & 7.77 & 2.46 & -0.08 & 0.90 & 1.22 & 0.48 & 5,126 \\
\hline NLD & 7.82 & 1.53 & 0.18 & 0.89 & 1.15 & 0.32 & 5,119 \\
\hline PER & 7.53 & 2.38 & -0.19 & 0.81 & 1.25 & 0.44 & 6,493 \\
\hline POL & 7.19 & 2.30 & -0.25 & 0.95 & 1.32 & 0.51 & 4,400 \\
\hline PRT & 7.37 & 2.01 & 0.09 & 0.98 & 1.20 & 0.44 & 7,114 \\
\hline QAT & 7.42 & 2.51 & -0.06 & 1.00 & 1.38 & 0.63 & 10,650 \\
\hline $\mathrm{QCH}$ & 6.98 & 2.32 & -0.29 & 0.80 & 1.32 & 0.52 & 9,719 \\
\hline QES & 7.40 & 2.04 & 0.51 & 1.13 & 1.20 & 0.40 & 31,649 \\
\hline QUC & 7.38 & 2.11 & -0.02 & 1.04 & 1.22 & 0.41 & 1,573 \\
\hline QUE & 7.40 & 2.15 & -0.05 & 1.08 & 1.32 & 0.54 & 1,800 \\
\hline RUS & 7.74 & 2.29 & -0.37 & 0.79 & 1.33 & 0.51 & 5,598 \\
\hline SVK & 7.47 & 2.24 & -0.27 & 0.83 & 1.32 & 0.54 & 5,928 \\
\hline SVN & 7.22 & 2.32 & -0.10 & 0.91 & 1.27 & 0.48 & 6,086 \\
\hline TAP & 6.62 & 2.12 & 0.03 & 0.96 & 1.15 & 0.34 & 7,644 \\
\hline THA & 7.69 & 2.08 & -0.32 & 0.66 & 1.40 & 0.66 & 7,863 \\
\hline TUN & 6.92 & 2.85 & -0.17 & 0.74 & 1.43 & 0.59 & 4,646 \\
\hline TUR & 6.11 & 2.93 & -0.42 & 1.12 & 1.24 & 0.51 & 5,612 \\
\hline
\end{tabular}


Table 1. Mean and standard deviation for life satisfaction, feelings of belonging, and bullying by country (Continued)

\begin{tabular}{|c|c|c|c|c|c|c|c|}
\hline \multirow[t]{2}{*}{ Country } & \multicolumn{2}{|c|}{ Life satisfaction } & \multicolumn{2}{|c|}{ Belonging } & \multicolumn{2}{|c|}{ Bullying } & \multirow[b]{2}{*}{$n$} \\
\hline & $M$ & $S D$ & $M$ & $S D$ & $M$ & $S D$ & \\
\hline URY & 7.76 & 2.20 & -0.05 & 1.11 & 1.27 & 0.52 & 5,538 \\
\hline USA & 7.36 & 2.20 & -0.07 & 1.01 & 1.29 & 0.50 & 5,509 \\
\hline
\end{tabular}

Note. Life satisfaction assessed on a 10-point-likert-scale, IRT score for feelings of belonging and mean score of the bullying items answerable on a 4-point Likert scale.

Table 2. Zero-order correlations for life satisfaction, bullying, and feelings of belonging

\begin{tabular}{lccc}
\hline & $(1)$ & $(2)$ & $(3)$ \\
\hline (1) Life Satisfaction & 1 & & \\
(2) Bullying & $-.19 *$ & 1 & \\
(3) Belonging & $.22 *$ & $-.22^{*}$ & 1 \\
\hline
\end{tabular}

Note. ${ }^{*} p<.001$ for all correlations

\section{Analysis 1: The Relation Between Bullying and Life Satisfaction}

First, we computed the main effect model predicting wellbeing from bullying. Results for the model with and without the main effects of the moderating variables are presented in Table 3. As proposed, the school-centered bullying of students predicts students' life satisfaction significantly, both in the model with the main effect of the moderator, $b=-0.82, p<.001$, and without this main effect, $b=-1.03, p<.001$. Students with a bullying score one point above their group mean on the 4-point scale report one point less life satisfaction on the 10-point scale compared with students with a bullying score of one standard deviation below the mean. Another significant predictor is the main effect of belonging, $b=0.43, p<$ .001. Further, likelihood ratio tests revealed random slopes of bullying to be significant on school, $\chi^{2}(2)=$ 1522.33, $p<.001$, as well as on country level, $\chi^{2}(2)=$ 216.96, $p<.001$. Therefore, we continued to examine belonging as a moderator of the association between bullying and life satisfaction. The control variables gender, socioeconomic status (ESCS) and migration status also predict life satisfaction significantly (see Table 3).

\section{Analysis 2: Belonging as Moderator for the Relation Between Bullying and Life Satisfaction}

Next, we entered the moderator, that is, the interaction between bullying and belonging. Information criteria, as

Table 3. Results of multi-level regression analyses for life satisfaction regressed on bullying, feelings of belonging, the interaction between bullying and belonging, and all covariates

\begin{tabular}{|c|c|c|c|}
\hline Parameter & Model 1 & Model 2 & Model 3 \\
\hline Constant & $7.22 *(0.07)$ & $7.22 *(0.07)$ & $7.24 *(0.07)$ \\
\hline Gender (Male) & $0.47 *(0.01)$ & $0.45^{*}(0.01)$ & $0.45 *(0.01)$ \\
\hline ESCS & $0.16 *(0.00)$ & $0.14^{*}(0.00)$ & $0.14^{*}(0.00)$ \\
\hline Migration status (first-generation) & $-0.24 *(0.02)$ & $-0.20 *(0.02)$ & $-0.21 *(0.02)$ \\
\hline Migration status (second-generation) & $-0.15^{*}(0.02)$ & $-0.15 *(0.02)$ & $-0.15 *(0.02)$ \\
\hline Bullying & $-1.03 *(0.03)$ & $-0.82 *(0.03)$ & $-0.75 *(0.02)$ \\
\hline Belonging & & $0.43 *(0.00)$ & $0.44 *(0.00)$ \\
\hline \multirow[t]{2}{*}{ Bullying*Belonging } & & & $0.18 *(0.00)$ \\
\hline & & lodel comparis & \\
\hline Observations & 319,057 & 319,057 & 319,057 \\
\hline Log likelihood & $-697,229$ & $-691,562$ & $-691,384$ \\
\hline AIC & $1,394,485$ & $1,383,153$ & $1,382,798$ \\
\hline $\mathrm{BIC}$ & $1,394,623$ & $1,383,302$ & $1,382,958$ \\
\hline$\chi^{2}$ diff & & & $356.88^{*}$ \\
\hline
\end{tabular}

Note. Standard errors are in parentheses. All predictors are group centered. Covariates are Gender, ESCS (economic and socioeconomic status), and migration status of first- and second-generation students. ${ }^{\star} p<.001$. 

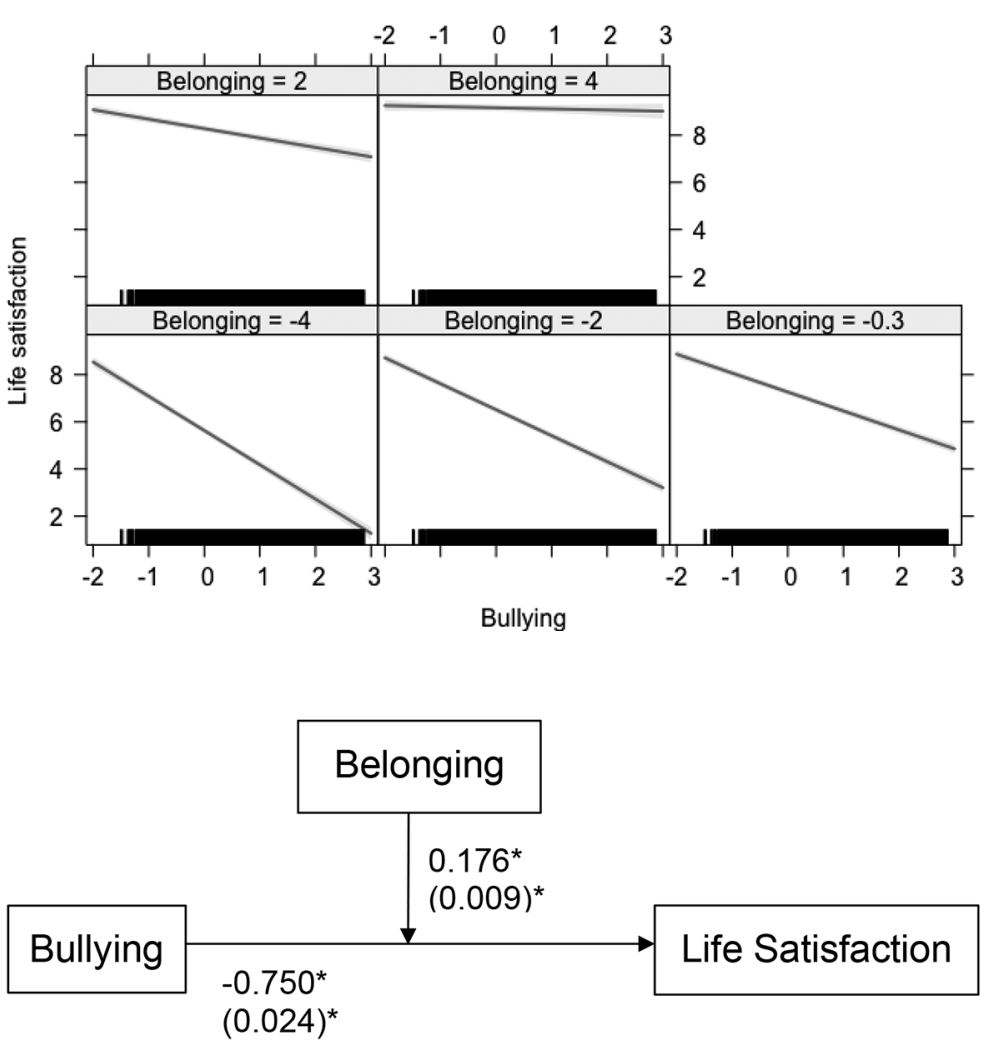

Figure 1. Relationship between bullying and life satisfaction by level of feelings of belonging with higher values representing higher levels of bullying, well-being, and feelings of belonging.

Figure 2. Results of multilevel regression analysis with $b$ coefficients and standard errors in parentheses. well as chi-square statistics, are in favor of the more complex model, indicating a significant amount of variance explained by the interaction, $\chi^{2}(1)=356.88, p<.001$ (see Table 3). In detail, the negative relation of bullying and life satisfaction was moderated by belonging: For students with higher belonging, bullying was less predictive for life satisfaction, $b=0.18, p<.001$ (see Figures 1 and 2). Therefore, the moderation hypothesis is supported. All coefficients can be found in Table 3 .

\section{Discussion}

In the present paper, we investigated whether feelings of belonging and of being respected and valued compensate for the negative effect that bullying has on one's wellbeing, which was operationalized by students' life satisfaction. We assumed that feelings of belonging would act as a compensator and, thus, would reduce the negative outcomes of being bullied on students' well-being. Therefore, we tested whether feelings of belonging moderate the relation between self-reported bullying and life satisfaction, that is, the cognitive component of subjective well-being, worldwide.

First, the results replicated the empirically well-investigated association between bullying and well-being: The more students reported getting called names, left out of activities or, even, getting hit by others, the less they reported being satisfied with their life. In line with previous research, the relation between self-reported bullying and life satisfaction was very strong, with a regression coefficient close to 1 . This finding is in line with prior research (e.g., Olweus \& Breivik, 2014, as an overview) and is not surprising given the huge significance for individuals to be accepted and liked by others (Baumeister \& Leary, 1995; Deci \& Ryan, 2008). While most prior studies focused on self-reported psychological and physical health-related symptoms such as depression, anxiety, stomach pains, and sleeping problems, our study is the first to focus on subjective well-being, or more specifically general life satisfaction. As stated earlier, the subjective well-being concept summarizes cognitive evaluations of different aspects of one's life.

Second, and in line with our expectations, the results indicate that belonging serves as a compensator: The more students feel accepted and valued by peers and other important people in their life, the less do experiences with bullying affect their well-being, that is, their life-satisfaction. On the basis of previous research (e.g., Walton \& Cohen, 2011), we assumed that feelings of belonging are a compensator because on the one hand, they change students' attributional patterns and on the other hand, belonging can be understood as a protective 
factor that contributes to children's and adolescents' resilience. Thus, we assumed that students who are bullied but - at the same time - also have strong feelings of belonging would report higher well-being than students with weaker feelings of belonging. The results indicate that feelings of belonging serve as a compensator and mitigate the negative effect of bullying on well-being. Regarding the model fit indices, both AIC and BIC indicate that including the interaction term increases the goodness of fit of the model. Thus, feelings of belonging seem to be an important factor.

From a theoretical as well as practical point of view, these findings are very important. First, from a theoretical point of view, we can see that feelings of belonging are a cross-cultural stable shielding factor against the negative effects of bullying. Second, the study findings are theoretically interesting as they provide deeper insight in the psychological processes underlying bullying consequences. Thus, not only bullying itself harms people, but also and even more so the momentous combination of being a victim of harmful behavior and not feeling accepted by others. We want to highlight that for persons with very high feelings of belonging, experienced bullying does not influence their subjective well-being substantially. From a practical point of view, this study provides information on how to develop educational settings: They should foster acceptance among students and focus on high belonging in addition to a focus on the avoidance of bullying. An environment of acceptance and appreciation should make students more resilient, especially against bullying (cf. Alizadeh et al., 2018; Lee \& Williams, 2013; Scarf et al. 2016). By contrast, focusing only on the avoidance of bullying might not be sustainable.

\section{Limitations}

The present study highlights the importance of belonging for individuals' well-being cross-culturally. We were able to show not only the well-investigated main effect of social belonging on subjective well-being, but also its compensating effect against bullying with a large sample of students in 47 different countries around the globe. The use of the PISA data enabled a cross-cultural approach. However, this dataset also has some disadvantages regarding internal validity. First, our results are crosssectional. Therefore, we cannot be sure about the direction of the underlying psychological processes. Future studies have to investigate further the causal relationship between bullying, belonging, and well-being, as we highlighted the global importance of these factors. However, numerous studies show that the negative consequences of being bullied can be long-standing and last for a lifetime (see, e.g., the findings of a meta-analysis by Ttofi et al., 2011). Therefore, even though our findings are crosssectional, they are in line with previous findings that are based on longitudinal data. Second, we were only able to rely on self-reports about bullying and belonging. Observational data of experimental manipulations of bullying and belonging cannot be gathered due to ethical concerns. However, self-reported bullying incidents and retrospective reports of having been bullied are, to some degree, reliable: For example, Rivers (2001) found that bullying reports do not vary greatly across a 12-14-month period, indicating a stable recall of bullying incidents.

Furthermore, although these results are in line with previous findings, the "well-being" item included in the PISA data actually measured "life satisfaction," the psychological component of well-being by asking: "Overall, how satisfied are you with your life as a whole these days?" Life satisfaction is considered a collective construct that has several facets (see Diener \& Diener, 1995) such as relationship satisfaction or financial satisfaction. Thus, one can argue that we did not use the appropriate scale for measuring students' well-being at school and, hence, our hypothesis is not tested with the appropriate data (see, e.g., OECD, 2013). Further, one can argue that more empirically well-tested well-being scales (with more than one item) exist that would produce more valid results. However, since the measure used is a collective one and the results show a very strong relation between bullying and this collective measure, our results can be considered as even more convincing and valid. However, as stated earlier, life satisfaction can be seen as the cognitive component of subjective well-being (cf. Schimmack et al., 2002). Thus, our research findings are limited to this cognitive component. To be able to draw a full picture of the relationship between bullying, belonging, and well-being, future research should investigate both components.

Also, the psychometric properties of the scales used here are not perfect (OECD, 2017b) but can be seen as sufficient. We rely on the build-in belonging indicator and the results of our confirmatory factor analysis on the bullying scale as sufficient indicators for measurement invariance. Using data from countries with different cultures and languages always involves problems regarding psychometrics. Therefore, we strongly recommend further replication of these findings on national samples. Another issue is the skewness of our mean score for the bullying scale - as most students report no bullying experiences. However, residual diagnostics do not indicate any violations of the assumptions of linear regression models and we were able to observe stable effects even though there was no large variance in bullying and wellbeing. 
Lastly, all analyses were conducted cross-country controlling for shared environments and variances. We aimed to establish general psychological principles applicable worldwide and not to investigate differential effects between countries and cultures. However, cultural contexts might alter the association between bullying and well-being in general depending on the cultural dimension such as individualism/collectivism (Triandis, 1995) or the compensating effect of belonging. Such contextual moderators on country level should be investigated further.

\section{Practical Implications and Future Directions}

With regard to practical implications, the findings indicate that strengthening students' feelings of belonging in their school is a powerful preventive tool. Belonging can be understood as a protective factor that contributes to children's and adolescents' resilience in the context of bullying. Thus, schools should generally strive to enhance students' feelings of belonging to their school in order to increase their well-being and better equip them against bullying. Several researchers already developed and tested psychological interventions to strengthen students' feelings of belonging. Walton and Cohen (2007, 2011) developed a particularly effective social-belonging intervention. This intervention is not only supportive for minority students in the secondary but also in the primary school context: For example, it supports minority 6thgrade students during transition to middle school (Goyer et al., 2019) as well as minority high school graduates during transition to university (Walton \& Brady, 2017). Further, belonging interventions should be part of general social skills training and programs to make children and adolescents more resilient against social issues such as bullying.

Also, school programs that are designed to prevent or reduce bullying at school should include parts that focus on enhancing students' belonging feelings. One empirically well-tested school program is Olweus Bullying Prevention Program (OBPP; e.g., Olweus, 1993). It considers the achievement of better peer relations at school (besides reducing existing bullying problems and preventing the development of new bullying problems) as one primary goal. In order to reach these goals, the program suggests a restructuring of the school's environment by building - among other things - a "sense of community" among students and adults within this environment. Thus, it seems that strengthening students' feelings of belonging has already been a component of this program - even though it has not been explicitly stated. Summed up, based on the present findings, it seems to be very helpful to integrate belonging interventions in other programs as well.

Further and as stated earlier, the data used in the present study are cross-sectional and, thus, no causal conclusions can be drawn from the results. Therefore, future research should use longitudinal or experimental designs to test the aforementioned hypothesis. For example, in a longitudinal study, researchers could question students about their bullying experiences, their wellbeing, and their feelings of belonging over a longer period. Another way is to experimentally vary students' feelings of belonging, for example, via a belonging intervention. A pre-post follow-up design can be implemented and measure students' bullying experiences as well as their well-being before and after the intervention took place.

Taken together, students are individuals and there is no "one-size-fits-all" approach (cf. OECD, 2017a) to prevent children and adolescents from being a victim of bullying. What is evident from the present results is that schools must promote an environment of acceptance, inclusion, respect, and appreciation among students worldwide. Further, more causal-oriented studies can clarify what schools can effectively do to protect children and adolescents during this crucial developmental phase. As some bullying prevention programs already do, interventions to promote belonging feelings should be part of these programs. With that, results of bullying prevention programs can be sustainable and long-lasting. Summed up, although there is already substantial research on determinants and consequences of being bullied and several wellinvestigated intervention programs exist, more research on this very important topic is still urgently needed.

\section{References}

Alizadeh, S., Khanahmadi, S., Vedadhir, A., \& Barjasteh, S. (2018). The relationship between resilience with self-compassion, social support and sense of belonging in women with breast cancer. Asian Pacific Journal of Cancer Prevention, 19(9), 2469. http://dx.doi.org/10.22034/APJCP.2018.19.9.2469

Alsaker, F. D. (2016). Mutig gegen Mobbing in Kindergarten und Schule (2nd ed.). Hogrefe.

Austin, S., \& Joseph, S. (1996). Assessment of bully/victim problems in 8- to 11-year-olds. British Journal of Educational Psychology, 66(4), 447-456. http://dx.doi.org/10.1111/j.20448279.1996.tb01211.x

Bates, D., Mächler, M., Bolker, B., \& Walker, S. (2014). Fitting linear mixed-effects models using Ime4. arXiv:1406.5823 [stat]. http://arxiv.org/abs/1406.5823

Baumeister, R. F., \& Leary, M. R. (1995). The need to belong: Desire for interpersonal attachments as a fundamental human motivation. Psychological Bulletin, 117(3), 497-529. http://dx.doi. org/10.1037/0033-2909.117.3.497 
Blazer, C. (2005). Literature review on bullying. Report for the office of accountability and systemwide performance of the MiamiDade county school board. Miami-Dade County Public Schools.

Buhs, E. S. (2005). Peer rejection, negative peer treatment, and school adjustment: Self-concept and classroom engagement as mediating processes. Journal of School Psychology, 43(5), 407 - 424. https://doi.org/10.1016/j.jsp.2005.09.001

Buhs, E. S., Ladd, G. W., \& Herald, S. L. (2006). Peer exclusion and victimization: Processes that mediate the relation between peer group rejection and children's classroom engagement and achievement? Journal of Educational Psychology, 98(1), 1-13. http://dx.doi.org/10.1037/0022-0663.98.1.1

Carbone-Lopez, K., Esbensen, F.-A., \& Brick, B. T. (2010). Correlates and consequences of peer victimization: Gender differences in direct and indirect forms of bullying. Youth Violence and Juvenile Justice, 8(4), 332 -350. https://doi.org/10.1177/ 1541204010362954

Carle, A. C. (2009). Fitting multilevel models in complex survey data with design weights: Recommendations. BMC Medical Research Methodology, 49. https://doi.org/10.1186/14712288-9-49

Carney, A. G., \& Merrell, K. W. (2001). Bullying in schools: Perspectives on understanding and preventing an international problem. School Psychology International, 22(3), 364-382. https://doi.org/10.1177/0143034301223011

Cheung, F., \& Lucas, R. E. (2014). Assessing the validity of singleitem life satisfaction measures: Results from three large samples. Quality of Life Research, 23(10), 2809-2818. https:// doi.org/10.1007/s11136-014-0726-4

Choenarom, C., Williams, R. A., \& Hagerty, B. M. (2005). The role of sense of belonging and social support on stress and depression in individuals with depression. Archives of Psychiatric Nursing, 19(1), 18 - 29. https://doi.org/10.1016/j.apnu.2004.11.003

Cohen, J., Cohen, P., West, S. G., \& Aiken, L. S. (2003). Applied multiple regression/correlation analysis for the behavioral sciences. Erlbaum.

Cook, C. R., Williams, K. R., Guerra, N. G., Kim, T. E., \& Sadek, S. (2010). Predictors of bullying and victimization in childhood and adolescence: A meta-analytic investigation. School Psychology Quarterly, 25(2), 65-83. https://doi.org/10.1037/a0020149. supp

Deci, E. L., \& Ryan, R. M. (2008). Self-determination theory: A macrotheory of human motivation, development, and health. Canadian Psychology/Psychologie Canadienne, 49(3), 182 - 185. https://doi.org/10.1037/a0012801

Diener, E., \& Diener, M. (1995). Cross-cultural correlates of life satisfaction and self-esteem. Journal of Personality and Social Psychology, 68(4), 653-663. https://doi.org/10.1037/00223514.68.4.653

Enders, C. K., \& Tofighi, D. (2007). Centering predictor variables in cross-sectional multilevel models: A new look at an old issue. Psychological Methods, 12(2), 121-138. https://doi.org/ 10.1037/1082-989X.12.2.121.supp

Esbensen, F.-A., \& Carson, D. C. (2009). Consequences of being bullied: Results from a longitudinal assessment of bullying victimization in a multisite sample of American students. Youth and Society, 41(2), 209-233. https://doi.org/10.1177/ $0044118 \times 09351067$

Eslea, M., Menesini, E., Morita, Y., O’Moore, M., Mora-Merchán, J. A., Pereira, B., \& Smith, P. K. (2004). Friendship and loneliness among bullies and victims: Data from seven countries. Aggressive Behavior, 30(1), 71 -83. https://doi.org/10.1002/ab.20006

Ganotice, F. A., \& King, R. B. (2014). Social influences on students' academic engagement and science achievement. Psychological Studies, 59(1), 30-35. https://doi.org/10.1007/s12646-0130215-9
Goyer, J. P., Cohen, G. L., Cook, J. E., Master, A., Apfel, N., Lee, W., Henderson, A. G., Reeves, S. L., Okonofua, J. A., \& Walton, G. M. (2019). Targeted identity-safety interventions cause lasting reductions in discipline citations among negatively stereotyped boys. Journal of Personality and Social Psychology, 117(2), 229 259. https://doi.org/10.1037/pspa0000152.supp

Gunn, J. F. III, Lester, D., Haines, J., \& Williams, C. L. (2012). Thwarted belongingness and perceived burdensomeness in suicide notes. Crisis, 33(3), 178-181. https://doi.org/10.1027/ 0227-5910/a000123

Hagerty, B. M. K., Lynch-Sauer, J., Patusky, K. L., Bouwsema, M., \& Collier, P. (1992). Sense of belonging: A vital mental health concept. Archives of Psychiatric Nursing, 6(3), 172-177. https://doi.org/10.1016/0883-9417(92)90028-H

Hawker, D. S. J., \& Boulton, M. J. (2000). Twenty years' research on peer victimization and psychosocial maladjustment: A metaanalytic review of cross-sectional studies. Journal of Child Psychology and Psychiatry, 41(4), 441-455. https://doi.org/ 10.1111/1469-7610.00629

Hazler, R. J. (1996). Breaking the cycle of violence: Interventions for bullying and victimization. Accelerated Development.

Hofmann, D. A., \& Gavin, M. B. (1998). Centering decisions in hierarchical linear models: Implications for research in organizations. Journal of Management, 24(5), 623-641. https://doi. org/10.1177/014920639802400504

Hoyle, R. H., \& Crawford, A. M. (1994). Use of individual-level data to investigate group phenomena: Issues and strategies. Small Group Research, 25(4), 464-485. https://doi.org/10.1177/ 1046496494254003

Hutzell, K. L., \& Payne, A. A. (2012). The impact of bullying victimization on school avoidance. Youth Violence and Juvenile Justice, $\quad$ 10(4), $\quad 370-385 . \quad$ https://doi.org/10.1177/ 1541204012438926

Juvonen, J. (2006). Sense of belonging, social bonds, and school functioning. In P. A. Alexander \& P. H. Winne (Eds.), Handbook of educational psychology (pp. 655-674). Lawrence Erlbaum Associates Publishers.

Kaltiala-Heino, R., Rimpelä, M., Rantanen, P., \& Rimpelä, A. (2000). Bullying at school - an indicator of adolescents at risk for mental disorders. Journal of Adolescence, 23(6), 661-674. https://doi.org/10.1006/jado.2000.0351

Kanetsuna, T., \& Smith, P. K. (2002). Pupil insights into bullying, and coping with bullying: A bi-national study in Japan and England. Journal of School Violence, 1(3), 5-29. https://doi.org/ 10.1300/J202v01n03_02

Kuznetsova, A., Brockhoff, P. B., \& Christensen, R. H. B. (2014). ImerTest: Tests for random and fixed effects for linear mixed effect models. $R$ package version 2.0-11. CRAN-Package ImerTest. https://cran.r-project.org/package=lmerTest

Lee, H., \& Williams, R. A. (2013). Effects of parental alcoholism, sense of belonging, and resilience on depressive symptoms: A path model. Substance Use and Misuse, 48(3), 265-273. https://doi.org/10.3109/10826084.2012.754899

Maslach, C., Jackson, S.E., Leiter, M. P., Schaufeli, W. B., \& Schwab, R. L. (1986). Maslach burnout inventory (3rd ed.). Consulting Psychologists Press.

Nash, J. C., \& Varadhan, R. (2011). Unifying optimization algorithms to aid software system users: Optimx for R. Journal of Statistical Software, 43(9), 1-14. https://doi.org/10.18637/jss. v043.i09

Northwest Regional Educational Laboratory. Schoolwide Prevention of Bullying. (2001). Nwrel. http://www.nwrel.org.

Organization for Economic Cooperation and Development. (2013). OECD guidelines on measuring subjective well-being.

Organization for Economic Cooperation and Development. (2017a). PISA 2015 results (Vol. III): Students' well-being. 
Organization for Economic Cooperation and Development. (2017b). PISA 2015 technical report.

Olweus, D. (1993). Bullying at school: What we know and what we can do. Blackwell. https://doi.org/10.1002/pits.10114

Olweus, D. (1996). Revised Olweus bully/victim questionnaire. British Journal of Educational Psychology. https://dx.doi.org/ 10.1037/t09634-000

Olweus, D., \& Breivik, K. (2014). Plight of victims of school bullying: The opposite of well-being. In A. Ben-Aryeh, F. Casas, I. Frønes, \& J. E. Korbin (Eds.), Handbook of child well-being (pp. $2593-$ 2616). Springer.

Olweus, D., \& Limber, S. P. (2010). Bullying in school: Evaluation and dissemination of the Olweus Bullying Prevention Program. American Journal of Orthopsychiatry, 80(1), 124-134. https:// doi.org/10.1111/j.1939-0025.2010.01015.x

Rigby, K. (2003). Consequences of bullying in schools. The Canadian Journal of Psychiatry/La Revue Canadienne de Psychiatrie, 48(9), $\quad 583-590 . \quad$ http://dx.doi.org/10.1174/ 02103700360536428

Rivers, I. (2001). Retrospective reports of school bullying: Stability of recall and its implications for research. British Journal of Developmental Psychology, 19(1), 129 -141. https://doi.org/10. 1348/026151001166001

Roseth, C. J., Johnson, D.W., Johnson R. T. (2008). Promoting early adolescents' achievement and peer relationships: The effects of cooperative, competitive, and individualistic goal structures. Psychological Bulletin, 134(2), 223-246. http://dx.doi.org/ 10.1037/0033-2909.134.2.223.supp

Scarf, D., Moradi, S., McGaw, K., Hewitt, J., Hayhurst, J. G., Boyes, M., Ruffman, T., \& Hunter, J. A. (2016). Somewhere I belong: Long-term increases in adolescents' resilience are predicted by perceived belonging to the in-group. British Journal of Social Psychology, 55(3), 588-599. https://doi.org/10.1111/bjso. 12151

Schimmack, U., Radhakrishnan, P., Oishi, S., Dzokoto, V., \& Ahadi, S. (2002). Culture, personality, and subjective well-being: Integrating process models of life satisfaction. Journal of Personality and Social Psychology, 82(4), 582-593.

Seals, D., \& Young, J. (2003). Bullying and victimization: Prevalence and relationship to gender, grade level, ethnicity, self-esteem, and depression. Adolescence, 38(152), $735-747$.

Skaalvik, E. M., \& Skaalvik, S. (2011). Teacher job satisfaction and motivation to leave the teaching profession: Relations with school context, feeling of belonging, and emotional exhaustion. Teaching and Teacher Education, 27(6), 1029-1038.

Solberg, M.E., \& Olweus, D. (2003). Prevalence estimation of school bullying with the Olweus bully/victim questionnaire. Aggressive Behavior, 29(3), 239 - 268. https://doi.org/10.1016/j. tate.2011.04.001

Triandis, H. C. (1995). Individualism and collectivism. Westview.

Ttofi, M. M., Farrington, D. P., Lösel, F., \& Loeber, R. (2011). Do the victims of school bullies tend to become depressed later in life?
A systematic review and meta-analysis of longitudinal studies. Journal of Aggression, Conflict and Peace Research, 3(2), 63 - 73. https://doi.org/10.1108/17596591111132873

United Nations Educational, Scientific, and Cultural Organization. (2019). Behind the numbers: Ending school violence and bullying. https://unesdoc.unesco.org/ark:/48223/pf0000366483

Van Orden, K. A., Cukrowicz, K. C., Witte, T. K., \& Joiner, T. E. (2012). Thwarted belongingness and perceived burdensomeness: Construct validity and psychometric properties of the Interpersonal Needs Questionnaire. Psychological Assessment, 24(1), 197215. https://doi.org/10.1037/a0025358.supp

Walton, G. M., \& Brady, S. T. (2017). The many questions of belonging. In A. J. Elliot, C. S. Dweck, \& D. S. Yeager (Eds.), Handbook of competence and motivation: Theory and application (2nd. ed., pp. 272 - 293). The Guilford Press.

Walton, G. M., \& Cohen, G. L. (2007). A question of belonging: Race, social fit, and achievement. Journal of Personality and Social Psychology, 92(1), 82-96. https://doi.org/10.1037/00223514.92.1.82

Walton, G. M., \& Cohen, G. L. (2011). A brief social-belonging intervention improves academic and health outcomes of minority students. Science, 331(6023), 1447 -1451. https://doi.org/ 10.1126/science.1198364

Walton, G. M., Logel, C., Peach, J. M., Spencer, S. J., \& Zanna, M. P. (2015). Two brief interventions to mitigate a "chilly climate" transform women's experience, relationships, and achievement in engineering. Journal of Educational Psychology, 107(2), 468 485. https://doi.org/10.1037/a0037461.supp

Weiner, B. (2010). The development of an attribution-based theory of motivation: A history of ideas. Educational Psychologist, 45(1), 28 - 36. https://doi.org/10.1080/00461520903433596

Wentzel, K. R., Barry, C. M., Caldwell K. A. (2004). Friendships in middle school: Influences on motivation and school adjustment. Journal of Educational Psychology, 96(2), 195-203. https://doi.org/10.1037/0022-0663.96.2.195

\section{Funding}

Open access publication enabled by University of Mannheim.

\section{ORCID}

Dr. Tamara Marksteiner

(iD) https://orcid.org/0000-0002-8522-8957

\section{Dr. Tamara Marksteiner}

Department of Educational Psychology

University of Mannheim

68131 Mannheim

t.marksteiner@uni-mannheim.de 